\title{
DeteCtion OF CIRCULATING AND fECAL TRICHINELLA SPIRALIS ANTIGENS DURING EXPERIMENTAL INFECTION USING MONOCLONAL ANTIBODIES AGAINST THE NEW BORN LARVAE
}

\author{
DE-LA-ROSA J.-L.*, MORAN-TLATELPA E.*, MEDINA Y.**, GOMEZ-PRIEGO A.**** \& CORREA D.**
}

\section{Summary :}

Different assays to detect antigens of Trichinella spiralis during current infection have been standardized, although sensitivity values have been the main limitation to use them as routine diagnostic test. We report the production and use of monoclonal antibodies (MAbs) against the new born larvae which recognize both somatic and metabolic antigens from adult and muscular larvae (ML). We used two lgG3 MAbs (4B1, 4B2) and two lgG2a $(2 D 3,2 D 4)$ to detect antigens during experimental infection. All MAbs detect fecal antigens starting the second to third week post infection (wpi), although it was less clear with MAbs $4 \mathrm{~B} 1$ and $4 \mathrm{~B} 2$, while circulating antigens were detected from third to fourth wpi. Thus, the recognition of shared antigens among $T$. spiralis developmental stages can be used for early diagnosis of trichinellosis.

KEY WORDS : Trichinella, antigens, monoclonal-antibody, diagnosis, new born larva

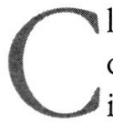
linical diagnosis of trichinellosis is supported by direct observation of the infective larvae (ML) in the skeletal muscles or by antibodies detection by ELISA or Western blot. However, these determinations are only possible up to the three to four week post-infection (wpi), which limits early administration of the treatment. Since the new born larvae (NBL) is an intermediate stage in the development of T. spiralis (between adults and ML) and against which the host has not yet built up a protective immune response, it makes an ideal target to attempt an early diagnosis by detecting antigens. Thus, the aim of this work was to produce monoclonal antibodies (MAbs) against the NBL and use them to detect antigenemia and coproantigens in an experimental model of trichinellosis.

* Zoonosis and **Biotechnology Departments, INDRE, Ministry of Health.

*** Faculty of Medicine, UNAM

Correspondence: J.-L. De La Rosa, Carpio 470, México D. F. 11340. Mexico.

Tel.: (525)3414953 ext. 224. - Fax: (525)3413264.

E-mail: indre@mail.ssa.gob.mx.
MATERIALS AND METHODS

\section{EXPERIMENTAL MODEL}

V V istar rats were orally infected with $28 \mathrm{ML}$ per gram of body weight. At day 40 post-infection, rats were killed with ether and the carcasses where artificially digested to recover ML. Feces and serum samples of rats were weekly collected during the course of infection and kept frozen until use.

\section{PARASITE ANTIGENS}

Crude extracts of ML, adult worms and NBL were prepared as described elsewhere (Parkhouse et al., 1981). After protein quantification, protease inhibitors were added and the antigens were kept frozen until its use. Excretory and secretory products of $\mathrm{ML}$ and adult worms, were obtained. Briefly, worms were cultured in vitro in RPMI 1640 medium (Gibco) supplemented with a diluted antibiotic-antimycotic solution (Gibco) for 48 hours at $37^{\circ} \mathrm{C}$ in a humidified $5 \% \mathrm{CO}_{2}$ atmosphere. Culture supernatants were collected and after protein concentration was determined, protease inhibitors were added and were kept frozen until use.

\section{MONOCLONAL ANTIBODIES}

$\mathrm{Balb} / \mathrm{c}$ mice were repeatedly immunized by intraperitoneal route with $50 \mu \mathrm{g}$ of NBL extract using Freund's complete (once) and incomplete (four) adjuvant (Sigma). Last injection was done by intravenous route without adjuvant. Spleen cells were fused with murine myeloma cells (X63/Ag 8.653) with polyethylene glycol 4000 (Gibco). Cells were cultured during three weeks in RPMI 1640 medium (Gibco) supplemented with inactivated foetal bovine serum (15\%), antibiotics (streptomycin/penicillin), L-glutamine, azaserine, and hypoxantine-amethopterin-thymidine (HAT medium). Surviving cells were maintained in culture by two additional weeks in the same medium but without azaserine. Supernatants were recovered and tested by standard ELISA. Cells of selected wells were cloned by 
limited dilution. All further assays were performed with supernatants as a source of antibody (MAb).

\section{CHARACTERIZATION OF MABS}

Four MAbs were selected. Immunoglobulin (Ig) isotypes were determined by ELISA using peroxidase conjugated anti-mouse Ig specific antibodies (Sigma), and reactions were developed with OPD and $\mathrm{H}_{2} \mathrm{O}_{2}$. MAbs cross-reactivity was tested by standard ELISA using antigenic extracts of $T$. taeniaeformis (cysticerci and larvae), Ascaris suum and $F$. hepatica adult worms, as well as the excretory-secretory products of $T$. solium cysticerci, kindly donated by Drs. G. Avila and A. Plancarte (UNAM; México).

\section{ANTIGEN DETECTION}

Feces from infected and non-infected rats were treated as described by Allan et al. (1990) and used for coproantigens detection in Dot-blot and ELISA. Five microlitre of each feces supernatant were adsorbed to nitrocelullose membrane, using a Dot-apparatus (Bio Rad) or $100 \mu \mathrm{L}$ from 1:20 dilution of supernatant were used to coat ELISA plates (Costar). Fecal antigens were detected using $100 \mu \mathrm{L}$ MAbs supernatant and peroxidase conjugated anti IgG mouse (Sigma). Reaction was developed with DAB in Dot-blot or with OPD in ELISA. To detect antigenemia, serum samples were diluted 1:100 and used to coat ELISA plates; antigens were detected as described above.

\section{RESULTS AND DISCUSSION}

Men clones of hybridoma secreting antibodies against $T$. spiralis antigens were obtained and

1 four of them were selected to determine antigenemia and coproantigens in experimental infections. Two MAbs were IgG3 isotype (4B1 and 4B2) and two other Mabs were IgG2a (2D3 and 2D4), all reacted to the ML, adult and NBL antigens (crude extract and excretory-secretory products) but none of them reacted to crude extract of other parasites. Unlike previous publication (Ortega-Pierres et al., 1996) these MAbs recognizes sharing epitopes between several antigenic compartments from all $T$. spiralis developmental stages. As shared epitopes were detected, we examined if these MAbs detected antigens in feces and serum samples obtained from experimentally infected rats. Fecal antigens were clearly detected by Dot-blot as early as the second week post infection (wpi) by MAbs 2D3 and 2D4 (Fig. 1). Although less clear, MAbs $4 \mathrm{~B} 1$ and $4 \mathrm{~B} 2$ also detected coproantigens at the same week. These data correlate with the trichinellosis enteric phase, i.e., presence of adult worms in the

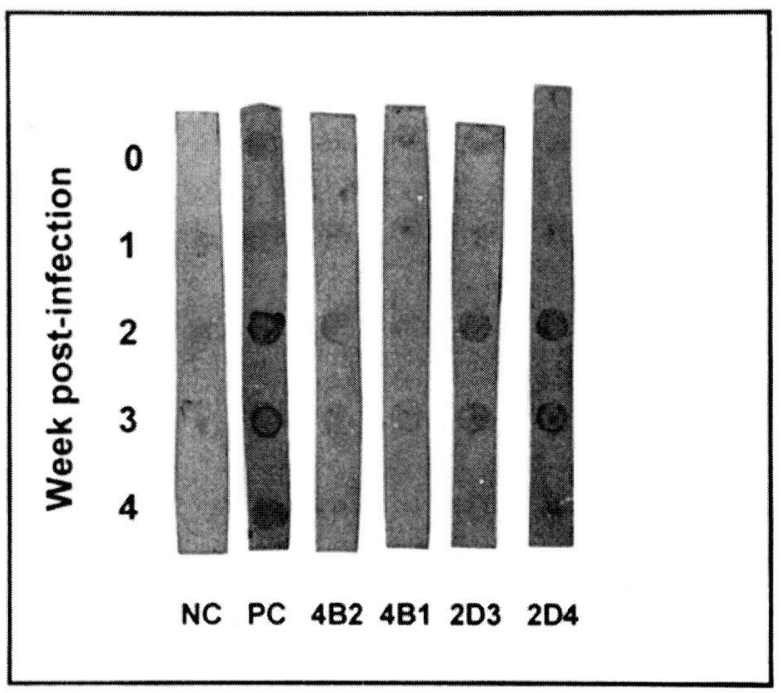

Fig. 1. - Detection of fecal antigens (Dot-blot).

Fecal supernatants were obtained at $0,1,2,3$ and 4 week post infection. Antigens were detected using four monoclonal antibodies (4B1, 4B2, 2D3 and 2D4). Reaction using non-immune mouse serum (NC) or hyperimmune mouse serum (PC) are also shown.

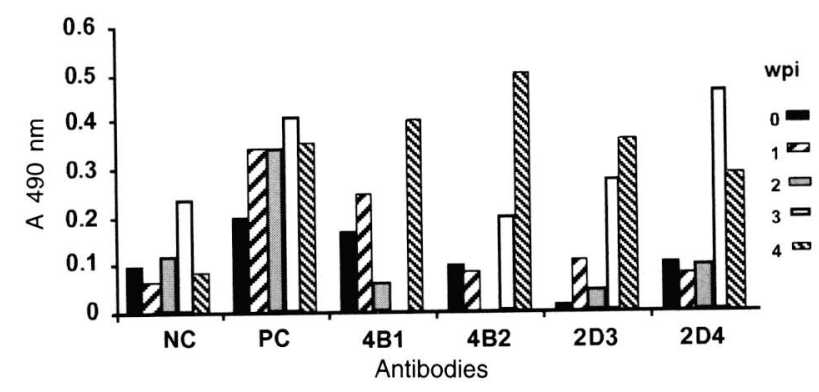

Fig. 2. - Detection of circulating antigens (ELISA).

Serum samples were obtained at $0,1,2,3$ and 4 week post infection and were adsorbed to plates and incubated with the supernatant from hybridoma cultures (4B1, 4B2, $2 \mathrm{D} 3$ and 2D4). Nonimmune mouse serum (NC), as well as hyperimmune mouse serum (PC) were used as negative and positive controls.

intestine. On the contrary, antigenemia were differentially detected by these MAbs since only MAb 2D4 reacted at the third week, while all the other MAbs reacted at the fourth wpi (Fig. 2), correlating also with the establishment of NBL in the skeletal muscle. Previous efforts to detect circulating antigens have been limited for diagnostic use, because the complexity of the assays or to its low diagnostic sensitivity (de-la-Rosa et al., 1996; Dzbenski et al., 1994; Ivanoska et al., 1989; Li \& Ko, 1996; Nishiyama et al., 1992). The results herein presented, suggest that coproantigens can be early detected with MAb's 2D3 and 2D4 used in a simple immunoenzymatic assay as Dot-blot. However, more experiments are needed to determine its usefulness for early diagnosis of trichinellosis. 


\section{ACKNOWLEDGEMENTS}

This work was partially supported by CONACyT, México grant 26169-B. We are thankful to L. Crecencio, Y. Islas, S. Zamora, N. Alvarez and R. Mendoza for excellent laboratory assistance. Rats and mice were provided by the INDRE animal house.

\section{REFERENCE}

Allan J., Avila G., Garcia-Noval J., Flisser A. \& Craig P. Immunodiagnosis of teniasis by coproantigen detection. Parasitology. 1990, 101, 473-477.

De-la-Rosa J. L., Mora J., TApia R. \& Correa D. Search of circulating antigens in the serum of experimentally infected rats with Trichinella spiralis by ELISA and western blot, in: Proceedings of the Ninth International Conference on Trichinellosis. Ortega-Pierres G., Gamble R., vanKnapen F., Wakelin D. (eds), CINVESTAV, IPN, México, 1996, 475-480.

DzBenski T. H., Bitkowska E. \& Plonka W. Detection of a circulating parasitic antigen in acute infections with Trichinella spiralis: diagnostic significance of findings. Zentralbl Bakteriol, 1994, 281, 519-525.

ivanoska D., Cuperlovic K., Gamble H. R. \& Murrell K. D. Comparative efficacy of antigen and antibody detection test for human trichinellosis. Journal of Parasitology, 1989, 75, 38-41.

Li C. \& Ko R. Detection of circulating antigens in acute trichinellosis, in: Proceedings of the Ninth International Conference on Trichinellosis. Ortega-Pierres G., Gamble R., van-Knapen F., Wakelin D. (eds), CINVESTAV, IPN, México, 1996, 489-495.

Nishiyama T., Araki T., Mizuno N., Wada T., Ide T. \& YamaGUCHI T. Detection of circulating antigens in human trichinellosis. Transaction of the Royal Society of Tropical Medicine and Hygiene, 1992, 86, 292-293.

Ortega-Pierres G., Yépez L., Homan W., Gamble H. R., Lim P. L., Takahashi Y., Wassom D. L. \& Appleton J.A. Workshop on a detailed characterization of Trichinella spiralis antigens: a platform for future studies on antigens and antibodies to this parasite. Parasite Immunology, 1996, 18, 273-284.

Parkhouse R. M. E., Philipp M. \& OGILvie B.M. Characterization of surface antigens of Trichinella spiralis infective larvae. Parasite Immunology, 1981, 3, 339-352. 